\title{
An Acoustic Study of English Word Stress of Amdo English Learners
}

\author{
Qian Zhou \\ Key Laboratory of China's Ethnic Languages and Information Technology of Ministry of Education, School of Foreign \\ Language, Northwest Minzu University, Lanzhou, Gansu 730000, China \\ Yonghong Li \\ Key Laboratory of China's Ethnic Languages and Information Technology of Ministry of Education, Northwest Minzu \\ University, Lanzhou, Gansu 730000, China \\ Lei Guo \\ Key Laboratory of China's Ethnic Languages and Information Technology of Ministry of Education, Northwest Minzu \\ University, Lanzhou, Gansu 730000, China
}

\begin{abstract}
This paper analyses the mastery of English word stress of China's Tibetan Amdo English learners, by means of acoustic phonetics. According to the "Negative Transfer" theory, as the mother language of Amdo doesn't have word stress, this will put negative influence to the learning of English stress and their pronunciation of it will be poor. However, the result of this study shows that these learners' grasp of English word stress is better than prediction, with an overall accuracy of $70 \%$ percent. Among the findings, two noticeable research result was discovered, which are the Amdo speakers' pronunciation of English words with stress on the first syllable (for words with multi-syllables), compound words with stress on the first word are quite problematic, and these speakers has no awareness of "stress shift". These findings are very helpful to Amdo English learners and their eachers and could be further used in pedagogy designs.
\end{abstract}

Index Terms — word stress, stress shift, negative transfer, English learning, acoustic study

\section{INTRODUCTION}

China has the most English learners in the world, and among these Tibetan learners are very important, as Tibetan is China's most important minority group and it has a population of 6 million( Tianlu Zhang, Mei Zhang,1993). They live in Tibetan Plateau and its neighborhood areas in China. Tibetan people share the same writing system but in terms of pronunciation, it has three dialects, Amdo, Kham and Tibet (Gesang Mianju, Gesang Yangjing, 2002), and among these, Amdo speakers consist half of the population. This study takes Amdo speakers as the research target, so the results of this study can be very influential to a huge body of language learners.

For some languages, word stress doesn't influence word meaning, like, Amdo, Chinese and Japanese, but in other languages like English, Russian, French and Polish, stress is a super segmental phoneme which means word stress does influence word meaning (Yuanren Zhao, 1980). And the "Negative Transfer" theory suggested that the learning of a new language can be greatly influenced by learners' mother language (Deng Siyi, 2018). So from the perspective of this theory, we can predict that the English pronunciation of Amdo speakers can be problematic. This paper is going to study the oral production of English word stress of Amdo English learners by means of acoustic analysis.

\section{WHAT IS WORD STRESS AND ITS ACOUSTIC CHARATERISTICS?}

In articulatory phonetics, when people articulate a syllable with greater force than other syllable in the same word, we call the syllable articulated with more force the stressed syllable. In phonetics, when indicate the pronunciation of a word, the mark ", " would be put on the left upper side of the IPA to show the position of the stress for researchers and learners. Acoustically, the stressed syllable produces an effect of loudness (Shen Baojing, 2012). And if one sound recording is read into Praat (Praat is an often used acoustic analysis software by researchers of language.), Praat can produce an "intensity tier" which show the change of loudness of this read-sound. So, from the "intensity tier", we can clearly see which syllable is stressed (the detailed steps of operation are illustrated in part6).

\section{The Stress System OF Amdo LANGUAGE}

The large scale and organized research of Tibetan language was started in 1950s in China. (Ge Sang Mian Ju, Ge Sang Yang Jing, 2001)Many language investigating groups had been sent and visited Tibetan areas in northern part of China, and many research results were published afterwards. Then, in 1970s, with the popularity of acoustic phonetics, Tibetan language and its dialects was researched in by more scientific means. Although the quality research of the 
language is not much, but most of the previous and present studies showed that for each individual Amdo word, there is no especially strongly articulated syllable or syllables, which means no syllable is stressed in sigle Amdo word. In phonetics, we name this phenomenon as “Amdo language doesn't have word stress" (Duan Haifeng, 2012, p56).

But still some researchers tried to prove that Amdo does have word stress (Shuangchen Wang,2012), but the evidences are not enough and their research results are not that prevailing. So, at this stage of this study Amdo is taken as has no word stress. And all the predictions made in part 5 is based on this condition.

\section{THE STRESS SySTEM OF ENGLISH}

For each and every individual English word, at least one or more syllables should be stressed, the stressed syllables are articulated with more force and are more prominent.

And also, in English, for some words, "stress" is a super segmental phoneme, which means, the shift of positions of "stress" in one word can affect the meaning and grammar function of that word, and finally make it becomes two words (Zhou Kaocheng,2004). Examples are given as follows and all the explanations of the words come from the Cambridge Dictionary.

'content: when stress is put on the first syllable it is a noun. It has two basic meanings: 1) everything that is contained within something. 2)the amount of a particular substance contained in something.

con'tent: when stress is put on the second syllable it is an adjective. It means pleased with the situation or result.

'object: when stress is put on the first syllable it is a noun. It has two basic meanings 1)a reason for doing something, or the result you wish to achieve by doing it; 2)someone or something that causes particular feelings in or actions by others.

ob'ject: when stress is put on the second syllable it is a verb. It means to feel or express opposition to or dislike of something or someone.

\section{The Prediction Made from the Perspective of Negative Transfer Theory}

Negative transfer first started in the research field of behavioral psychology, later was applied into the language learning research. The counterpart of this theory is positive transfer and the two together belong to Language Transfer.

Language transfer, also known as L1 interference, linguistic interference, and cross linguistic influence, refers to speakers or writers applying knowledge from one language to another language. Or also say transfer of elements of one language into the learning of another. Elements may include phonological, grammatical, lexical, and orthographical. (Skiba, Richard, 1997)

Linguistic interference can result in correct language production called positive transfer. For example, the sentence patterns of Chinese follow the SVO structure and so do the English sentence patterns, so, because of the positive influence of their mother language, when the Chinese learn the English, it is easy for them to grasp the sentence patterns of English. However, language interference is most often discussed as a source of errors known as negative transfer, which occurs when speakers and writers transfer items and structures that are not the same in both languages. (Larry Selinker, 2009) or it can be said as "Errors in the learner's foreign language that can be traced back to the mother tongue." (Lott, D., 1983) For example, English diphthongs are considered as two vowels together, gliding from one to the other and they are transitional in nature (Lee S, Potamianos A, Narayanan S., 2014). So "the gliding process" is the characteristic of oral production of diphthongs. But when Japanese speaks English diphthongs, most primary learners always read the two vowels separately, and do not have the "gliding process", as their mother language doesn't have diphthongs. Another example, if the mother language of a person doesn't have the vowels of /e/and/æ/, but his or her new learning languages have these two sounds. It will be difficult for him or her to make a distinction between the two phonemes and be even more difficult to pronounce them correctly.

In this case, as Amdo language doesn't have word stress, we can predict that when English words are pronounced by Amdo English learners, their awareness of "word stress" would be poor, these speakers would be very likely to forget to put a stress or stresses on individual English words, especially, multi-syllable English words. And their pronunciation of the word pairs (which share the same spelling, same phoneme combination, but different positions of stress) would be the same (with no change of stress position). And their overall accuracy rate will not exceed $50 \%$.

This study is going to use acoustic evidence to check the above predictions. The acoustic research will be carried out like the following in part 6 .

\section{THE INTRODUCTION OF THE STEPS OF THE EXPERIMENT}

\section{A. Make a Reading List}

A reading list was made to check the readers' understanding and mastery of word stress from four different aspects. The four aspects are: words with two, three, four and five syllables; words with two stresses; word pairs with stress shifting; the stress of compound words.

The reading list was like the following (without the mark of stress positions) and their research purpose was marked before each line of words. These words are all chosen under one precondition which is the words presented on this 
reading list should be very simple and common vocabulary. So that, to make sure that the mistakes were not caused by not knowing the word but by their inner causes (the influence of their mother language.) (As if the mistake is caused by not knowing the words, this is like to ask a person who has never learned Japanese to read Japanese, the mistake could not reflect any systematic studying or learning problem.)

Part A:

Two syllable words: 'modern 'people be'gin suc'cess

Three syllable words: 'industry 'policy refu'gee 'cigarette ad'vantage re'public

Four syllable words: 'agriculture 'ordinary a'cademy de'mocracy

Five syllable words: con’temporary vo'cabulary

Part B:

Words with two stresses: 'Chi'nese 'thir'teen 'Indo'nesia 'Yang 'zijiang 'after'noon

Part C:

Stress shift: 'insult in'sult 'record re'cord 'increase inc'rease 'import im'port 'object ob'ject

Recheck stress shift: There are three 'objects in the room.

I ob'ject to your opinion.

Are you 'content with her answer?

The con'tent of her speech is very inspirational.

The 'record will be played three times.

Part D:

To re'cord the teacher's class is necessary.

The stress of compound words

with stress on the first word: 'blackboard 'handbag 'bookstore 'classroom

with stress on the second word: ma'ltreat ill'treat short'change cross-'section

with two stresses: 'second-'handed 'kind'hearted 'arm'chair 'four-'footed

Three word compounds: 'Brother-in-'law 'good-for-'nothing

The reading list are derivations of An Introduction of English Phonetics (Kaocheng Zhou, 2012)and English Pronunciation and Intonation for communication (Guizhen Wang,2005).

The word lists were given to the students 20 minutes before making the recordings for them to practice and get familiar with, but without any guidance or tutoring and without telling them the research purpose.

\section{B. Select Speakers}

10 speakers without clear accent when both speak English and Amdo were chosen from Amdo speakers aged at 20 to 22 in Northwest Minzu University in China. The English scores of last semester's final exam of the speakers are between 70 and 80 and are taken as B-level students. And they all scored at the same level (Their scores are between 70 to 80.) in the speaking screening test. The speaking screening test was given by an American foreign teacher by asking each student to read a short article chosen from their text book. And the foreign teacher was told about the research purpose of this screening test.

\section{Make Recordings}

The recordings were made with a digital audio recorder and a microphone at a standard sound recording room with no interruptions. The recordings were sampled by Auditon3.0, at $16 \mathrm{kHz}$ with 12 bits of amplitude resolution, on a standard computer and saved as wav. type document.

\section{Using Praat to Make Acoustic Analysis}

Praat is an often used software to make acoustic analysis of language. When a recording of a word or sentence is read by Praat, we can get the intensity of a specific time and the intensity line of a time period. And the intensity of the word or sentence can be further converted into "Intensity Tier" like the following picture. 


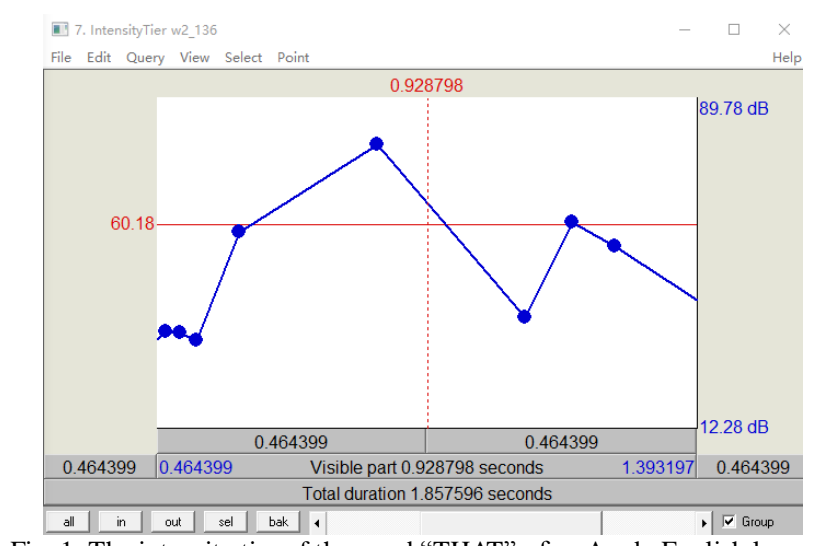

Fig. 1: The intensity tier of the word "THAT" of an Amdo English learner.

\section{E. Data Analysis}

In Fig1, the prominent part of the curve shows that the correspondent syllable is pronounced with more force and contains more energy. So, the intensity tier directly and clearly reflects which syllable is stressed in that recording, then, a judgment of whether the word is correctly or incorrectly pronounced by the speaker can be made. And finally, the accuracy rate of the speaker can be collected and calculated in excel by two third-year PH.D. students who's major is phonetics, working together.

\section{THE RESULtS OF THE RESEARCH}

Using the above method, this study has got the following results:

A. The Results of the Checking of the Free Stress of Words with Two, Three, Four and Five Syllables.

1. The accuracy rate of two syllable words is $75 \%$;

2. The accuracy rate of three syllable words is $68 \%$, however, there is a notable mistake, for the word " 'industry", all ten speakers mispronounced as "in'dustry". If this word is delated from calculation, the accuracy rate will rise to 75\%;

3. The accuracy rate for four syllable word is $44 \%$;

4. The accuracy rate of the five syllable word is $60 \%$.

And all the above data is made based on the following previous operation: three words (refugee, academy, contemporary) are deleted from the effective checking items, as these three words are read with clear phoneme mistake, hesitation and longer pauses by all ten students. This was taken as these students has not met and learned these words and the mistakes are caused not by the influence of the mother language but by not knowing the word at all. So these words was considered as uncommon words and deleted from final calculation.

\section{B. The Check of Words with Stress Shifting.}

The accuracy rate of "stress shifting" is $50 \%$, but this result should be explained as the Amdo speakers have no awareness of "stress shifting" at all. The reasons are as follows:

As what have been stated in part 6.1, the reading list for the checking of "stress shifting" consists two parts. The purpose of these two parts is the same, to check the speakers" awareness of "stress shifting".

The instruction of this part's reading list is quite clear, like the following picture:

\begin{tabular}{|l|l|}
3.1 请分别朗读下列动词的名词形式和动词形式 \\
\hline 名词 & 动词 \\
\hline insult & insult \\
\hline record & record \\
\hline increase & increase \\
\hline import & import \\
\hline object & object \\
\hline
\end{tabular}

Fig. 2: The picture of "stress shifting" on the reading list. Clear instruction (Read the noun form and verb form of the following words respectively) was given to the speakers above the table in Chinese.

But 5 of the speakers read each word only once (the other 5 speakers read the word pairs with no change of stress at all), this was considered as a test and instruction mistake at first and a supplementary test was prepared to give the speakers. But before given the test, a small questioner is sent to the speakers, the results showed that: the speakers all have noticed the instruction of reading the words separately and twice, but they all thought these words has no 
differences and read them only once.

Accept the above table which is designed to check "stress shift", the reading list also have six sentences with "stressshifting word pairs" in it to recheck the mastery of the "stress shifting". The result of this part also showed that "stressshifting word pairs" were read with no shifting of stress at all. Combine the questionnaire and the test, this study find out that Amdo English learners has no awareness of stress-shifting.

And also from these "stress- shifting word pairs", this study noticed that: when the word stress is on the first syllable, it is more likely for the speaker to mispronounce it (with an accuracy rate of 32\%); and also, when the stress is on the last syllable it is more likely to pronounce the word correctly (with an accuracy rate of 68\%).

\section{The Check of Compound Words}

1. For the two-word compounds which stress falls on the first word, the accuracy rate is $45 \%$;

2. For the two-word compounds which stress falls on the second word, the accuracy rate is $95 \%$;

3. For two-word compounds which have two word stress, the accuracy rate is $100 \%$;

4. For the three-word compounds, which stress falls on the first word, the accuracy rate is $90 \%$. These all together show that the grasp of the stress of compounds are generally good except for two word compounds with stress on the first word.

\section{CONCLUSION AND DISCUSSION}

In conclusion, this study has the following findings:

1) Generally, for the grasp of free stress, the accuracy rate is around $70 \%$;

2) For the grasp of word-stress shifting of multi-syllable words, Amdo speakers all don't have the awareness of word-stress shifting;

3) The speakers showed a tendency of pronounce the multi-syllable word with the stress not on the first syllable better;

4) For compound words, Except "the pronounce of the two-word compounds with the stress on the first word", the accuracy rates of the pronounce of the stress of compounds are very high(around 95\%). At the same time, this can be interpreted as a tendency of worse pronunciation towards the two-word compounds with stress on the first word.

These findings do not coincide with the predictions made in part 5 from two aspects: First, to a large extent, these B-level students all appear to grasped the using of stress of English (with an overall accuracy rate of 70\%).

Second, as according to the prediction, the mistake pattern of "stress" should be random and there would not show any tendency, but two obvious tendencies are shown in this study. And these two tendencies can be further concluded as one, which is, when stress is on the first syllable or first word, it is difficult for Amdo learners to pronounce.

This finding is very interesting, as what have been stated in part3, most of the very little previous studies of "word-stress" of Amdo Tibetan language all show that Amdo doesn't have "word-stress". However, according to the"Negative Transfer" theory, the learners' mother language can influence the learning of a new language and the form and pattern of mother language can be transferred to the learning language by not advanced learners. For example, Uighur language is one which all the stresses are on the last syllable of words, then, when Uighurs (beginner level) speak English multi-syllable words they tend to move all the stresses to the last syllable and mispronounce most of the words. So here, if we reverse the inference, about this finding, we can get that Amdo words should have word stress and the position of the stress are quite likely not on the beginning of the words.

This is like for Chinese, which belongs to the same language family with Tibetan, many basic theoretical issues of Chinese word stress still remain to be settled, and Chinese is also more often said to be no word stress as Tibetan. However, there are also discussions show that Chinese does have word stress and the position of the stress more tends to be on the end of the character. (Xu Laidi, 2018) (Zhou Ren, 2018) (Laidi Xu,2016)

\section{FUTURE RESEARCH INSPIRATIONS}

According to the above analysis, two further research inspirations can be given at here. First, a hypothesis is made as Amdo Tibetan words should have word stress and the position of the stress are quite likely not on the beginning of the words. Second, it deserves to look into Chinese word stress patterns by means of the research of second language learning. These two issues deserve further study and discussion. And these two tendencies also should be paid attention to when the English instructors teach Amdo English learners, so that the teaching and learning can be more effective.

\section{ACKNOWLEDGEMENTS}

This article was sponsored by Northwest Minzu University' research project; "The study of fossilization phenomenon of Tibetan English learners" (No: 31920180061); "The study of mispronunciation of super-segmental phoneme of Tibetan English learners" (No. Yxm2018012); The Education Research Project of Gansu Province" The supersegmental mistakes of English learners of Tibetans from Gansu Province" (GS[2018]GHBBK058) 


\section{REFERENCES}

[1] Deng Siyi. (2018). An overview of the interlanguage theory. Overseas English, 4, 237-256.

[2] Duan Haifeng. (2012). The Influence of Amdo Language to the learning of Chinese Tones. Beijing: Minzu University of China. 89-320.

[3] Gesang Mianju, Gesang Yangjing. (2001). Tibetan Language. Beijing:Minzu Press. 61-283.

[4] GeSang Mianju, GeSang Yangjing. (2001). An Introduction of Tibetan Dialects. Beijing: Minzu Press. 3-283.

[5] Guizhen Wang. (2005). English Pronunciation and Intonation for Communication. Beijing: Higher Education Press. 153-325

[6] Kaocheng Zhou. (2012). An Introduction to English Phonetics. Chengdu: Si Chuan University Press. 186-340.

[7] Laidi Xu. (2016). Several Basic Research Questions about Chinese Word Stress. The Journal of Foreign Language, 04, 78-82.

[8] Larry Selinker. (2009). IRAL - International Review of Applied Linguistics in Language Teaching. Interlanguage, 4, $133-267$.

[9] Lee S, Potamianos A, Narayanan S. (2014). Developmental acoustic study of American English diphthongs. The Journal of Acoustic Society of America, 136 (4),1880-1894.

[10] Lott, D. (1983). Analysing and counteracting interference errors, ELT Journal, 3, 256-261.

[11] Shen Baojing. (2012.05.)An Introduction to English Phonetics. Chengdu: Sichuan University Press. 180-279.

[12] Shuangchen Wang. (2012). A Research of Amdo Phonetics. Shanghai: Western and Eastern Publishing House.62-402.

[13] Skiba, Richard. (1997). Code Switching as a Countenance of Language Interference. The Internet TESL Journal, III, 10 .http://iteslj.org. (accessed 26/8/2019).

[14] Tianlu Zhang, Mei Zhang. (1993). Contemporary Tibetan Population. Beijing: China Social Science. 193-506.

[15] Xu Laidi. (2018). The Study of Several Theoretical Issues of Chinese Word Stress. Journal of Foreign Language, 04, 78-82.

[16] Yuanren Zhao. (1980). Language Study. Beijing: Commercial Press.

[17] Zhou Kaocheng. (2004). English Phonetics. Chengdu: Sichuan University Press. 180-364.

[18] Zhou Ren. (2018).Discussion and Thought: A retrospective review of Chinese Word Stress Review of Last 60 years. The Journal of Language Teaching and Research, 06, 102-112.

Qian Zhou was born in Shanxi, China in 1987. She is a third year PH.D. student in acoustic phonetics in Northwest Minzu University. She received her MA in Hong Kong Polytec University.

She is currently a lecturer in the School of Foreign Language in Northwest Minzu University, Lanzhou, China and used to be an assistant lecture in St. Edwards University, Austin, Taxes, the United States. Her research interests include acoustic phonetics and second language teaching.

She got TESOL EXPORT, TESOL ADVANCE, TESOL BUSINESS and TESOL CHILDREN in 2015, and won the United States Fulbright Scholarship in 2014 and worked and learned in the US for a year as a visiting scholar. She won the FIRST prize in the provincial level teaching contest in 2018 and 6 times got excellent mentor for provincial level speaking contest for students. Her published works include: ZHOU QIAN, (2019.09)The Facilitation of Modern Technics for English Pronunciation Class in Foreign Language Learning in China. Published by Proceedings of 2019 International Conference on Frontiers Technology of Information and Computers and waiting to be indexed by EI and Scopus; ZHOU QIAN,(2019.06)The Study of the Salient Vowel Mispronunciations of Tibetan Adult English Learners by Means of Experimental Phonetics. Published by Proceedings of 2019 the 9th International Workshop on Computer Science and Engineering and waiting to be indexed by EI and Scopus; ZHOU QIAN, (2019.01) Using Software to Visualize and Facilitate the Teaching of Vowels for Tibetan English Majors. Published by Proceeding of 2019 10th International Conference on E-Education, E-Business, E-Management and E-Learning (IC4E 2019) -- indexed by EI and Scopus.

Yonghong Li was born in Shanxi, China in 1979. He received his PH.D. degree in Northwest Minzu University. He is a professor and doctoral supervisor his major research interest is in the area of acoustic phonetics.

Lei Guo was born in Gansu, China in 1983. She received her PH.D. degree in Northwest Minzu University. She is an associate professor and her major research interests are in the area of acoustic phonetics and second-language learning. 